\title{
Não receptividade do pombo doméstico à infecção por Schizotrypanum $\left(^{*}\right)$
}

\author{
por \\ Emmanuel Dias
}

A imunidade das aves à infecção por Schizotrypanum é um fato geralmente admitido, pôsto que ainda insuficientemente provado. Nas escassas referências que se encontram na literatura à inoculação dêstes vertebrados com - agente da tripanosomose americana, o contrôle dos resultados negativos é quase sempre precário, não permitindo excluir a possibilidade de uma infecção inaparente.

As inoculações que relataremos a seguir, praticadas em pombo doméstico (Columba livia domestica) e controlada por xenodiagnósticos em série, além de documentarem de modo satisfatório a não receptividade desta ave à inoculação pelo esquizotripano, têm importância prática atual. De fato, na alimentação de barbeiros para criação "limpa" no laboratório para fins de xenodiagnóstico (método em grande voga para o diagnóstico de casos crônicos de moléstia de Chagas), o pombo é um animal correntemente empregado $(1,2)$; cumpre, portanto, bem estabelecer a sua imunidade natural ao agente etiológico, para saber se um pombo usado prèviamente na alimentação de barbeiros infétados, e exposto, por conseguinte, à infecção, poderá servir para nutrir insetos "limpos", sem risco de os contaminar.

\section{INOCULAÇŌES}

No dia 16 de outubro de 1942, dois pombos (n. 1.796 e 1.797 ) foram inoculados por via subcutânea, na face externa de uma das coxas, com vários centimetros cúbicos de sangue de cobaia $\left(n 0^{\circ} 1.734\right)$ intensamente infetada com uma amostra de Schizotrypanum isolada de caso agudo de moléstia de Chagas na Venezuela (3). Poucos exames de sangue foram feitos a fresco, sempre negativos, mas o xenodiagnóstico com barbeiros garantidamente puros foi praticado repetidamente e a curtos intervalos, durante pouco menos de um mês. Um dos pombos morreu em 28 de outubro de 1942, o outro em 10 de novembro de 1942 .

As primeiras provas foram feitas no mesmo dia da inoculação, 2-3 horas em seguida a esta. Outros detalhes sôbre os xenos acham-se abaixo especificados, tendo sido negativos todos os resultados. 


\section{XENODIAGNÓSTICOS}

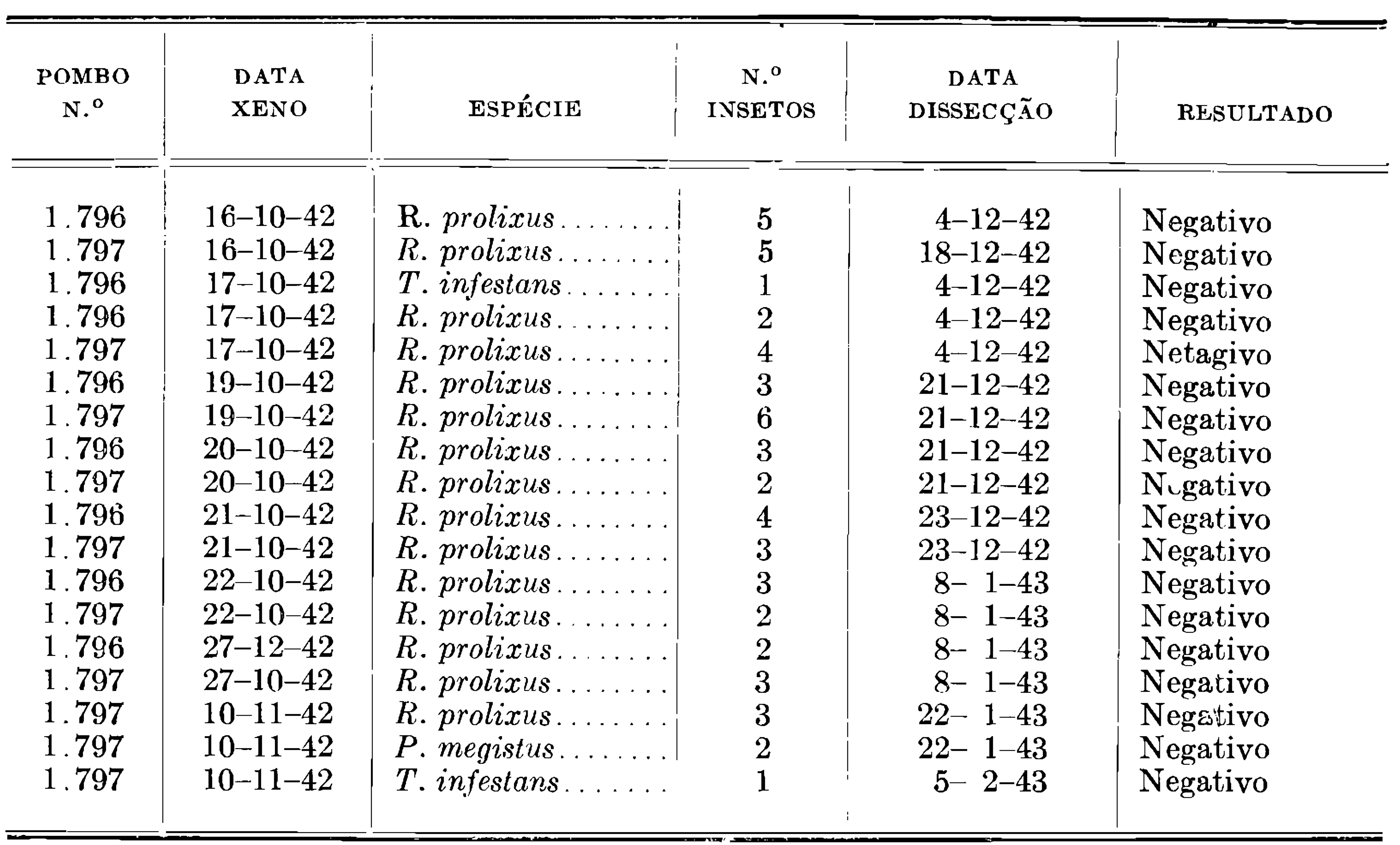

Foram portanto empregados 54 barbeiros que, dissecados a prazos convenientes após a sucção dos pombos inoculados, não adquiriram parasitismo por flagelados. O Rhodnius prolixus foi de preferência empregado, por ser a espécie mais comum na Venezuela, donde proveio também o esquizotripano com que trabalhamos.

(V. Dias, 1940, pág. 336: "Deve preferir-se, para o xenodiagnóstico em determinada região, uma espécie local, ou melhor, o transmissor natural mais importante da moléstia, nessa região).

Pelos resultados acima vê-se que não se pôde demonstrar, pelo xenodiagnóstico, a presença de parasitos no sangue dos pombos injetados com grande número de esquizotrípanos, nem mesmo nas primeiras horas e dias após a inoculação. Estas experiências são, pois, sugestivas de completa imunidade natural da Colımba livia domestica à infecção esquizotripanósica.

\section{S U M Á R I O}

Não foi conseguida a infecção de dois pombos por inoculação subcutânea de numerosas formas sanguicolas de Schizotrypanum, tendo sido negativos todos os xenodiagnósticos praticados desde três horas até 25 dias após a inoculação. 


\section{SUIMMARY}

Massive inoculation of two pigeons with blood forms of Schizotrypanum (human strain) did not produce infection, xenodiagnostics being negative from 3 hours to 25 days after inoculation.

\section{REFERENCIAS}

1. Dias, Emmanuel

1938. Criação de triatomideos no laboratório.

Memórias do Instituto Oswaldo Cruz 33 (3) : 407-412.

2. Dias, Emmanuel

1940. Técnica do xenodiagnóstico na moléstia de Chagas.

Memórias do Instituto Oswaldo Cruz 35 (2) : 335-342.

3. Dias, Emmanuel $\mathcal{E}$ Torrealba, J. F.

1943. Verificação de flagelados semelhantes ao Trypanosoma rangeli Tejera, em Rhodnius prolixus alimentados em caso agúdo de doença de Chagas na Venczuela. Considerações sôbre a natureza dêste protozoário.

Memórias do Instituto Oswaldo Cruz 39 3) : 256-278. 